\title{
YELLOW GRAY JAYS
}

SUSAN LINGLE'1, PETER IMHOF ${ }^{1}$ Department of Biology, University of Winnipeg

During the Easter weekend 2013, March 30 \& 31, we spent one afternoon at Emerald Lake, close to Field, BC, in Yoho National Park. With moderate temperatures, we walked on the ice of the lake clockwise along the shore, starting at Emerald Lake Lodge. At the northern edge of the lake, where we joined the otherwise snowed-over trail in the flood plain feeding the lake, we met a group of four birds, which can be most simply described as yellow gray jays. We encountered the birds along the path to the east of a bench (approximately 100-200 $\mathrm{m}$ ) which is located at a latitude of 51.4507 degrees $\mathrm{N}$ and longitude of 116.5328 degrees $W$. The birds approached us, called out, sat on a hand when it was offered and pecked it - as one would expect from typical jays. Their size and markings were consistent with adult gray jays, with a black cape behind their eyes, black bills, legs, and feet and lighter ear patches and throats. Peterson's Field Guide to Birds of Western North America, 4th edition, 2010, indicates regional variation in Gray Jays: Pacific, Northern, and Rockies. The Rockies gray jay variation has less black on the heads. For the birds we saw, the tops of the heads, areas around their ear patches and beaks, and parts of their stomachs and backs were yellow. Peterson's Field Guide gives no indication of such a colour variance in gray jays. We took some photographs as one of the birds remained perched on a finger. After a few minutes of excitement, we and the birds parted.

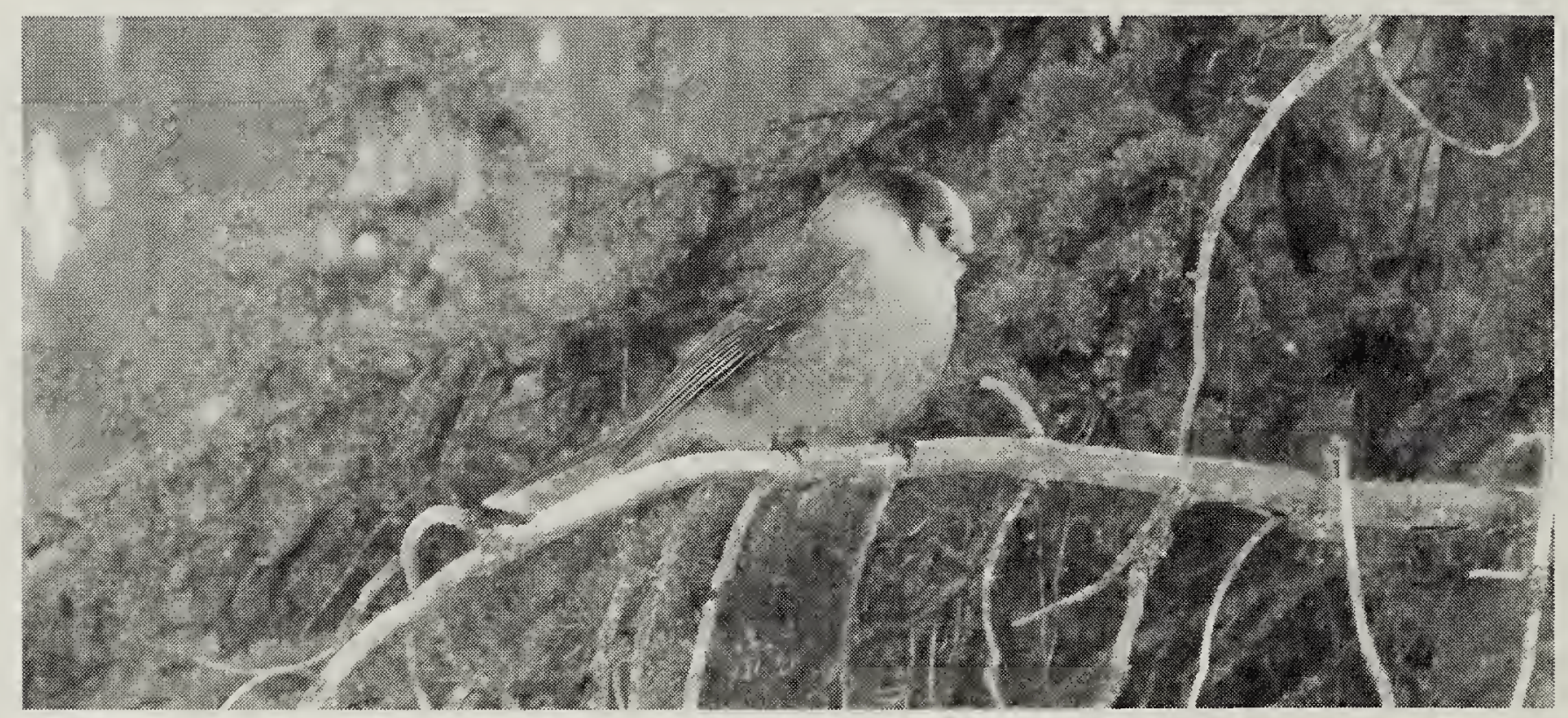

Yellow gray jays (Colour images on back inside cover) 